\title{
Evaluation of the pull-out strength of galvanised steel strips in a cement-based material
}

\author{
Maziar RAMEZANI ${ }^{\dagger}$, Juan VILCHES, Thomas NEITZERT \\ (Centre for Advanced Manufacturing Technology (CAMTEC), School of Engineering, \\ Auckland University of Technology, Auckland, New Zealand) \\ †E-mail: maziar.ramezani@aut.ac.nz
}

Received Apr. 2, 2013; Revision accepted Aug. 30, 2013; Crosschecked Nov. 27, 2013

\begin{abstract}
The study of the interfacial and bond behaviour of reinforced cement-based materials is important for understanding the mechanical behaviour of such composites. This paper presents extensive experimental, theoretical and finite element analyses of pull-out tests of galvanised steel strips with different geometries, in lightweight cement-based material blocks with different densities and mechanical properties. The theoretical model proposed here is capable of determining the pull-out strength and bond stress versus the slip relationship between components of reinforced cement-based materials. This bond-slip relationship is then implemented in finite element simulation through the user-defined subroutine of ABAQUS software. Based on the results, a trilinear bond-slip model is suitable for modelling the interface between a steel strip and a cement-based material interface.
\end{abstract}

Key words: Bond-slip relationship, Cement-based materials, Galvanised steel strip, Pull-out test doi: $10.1631 /$ jzus.A1300105

Document code: A

CLC number: TU50

\section{Introduction}

This research is part of a composite structural assembly (CSA) products project aimed at creating advanced composite materials and products using newly developed manufacturing technologies. CSAs were developed based on the high strength of locally manufactured light gauge steel in combination with other locally produced materials such as wood, concrete, glass-fibre, and gypsum. The novel combination of materials enabled each assembly to achieve performance standards well above those of the individual materials or existing building products.

The aims of the project were to identify performance requirements for CSAs, develop manufacturing concepts and processes, evaluate performance, conceptualise designs, outline pathways to market, and establish a sector group. Research was initially focused on the development of a prefabricated composite wall panel system and a prefabricated hollow

C) Zhejiang University and Springer-Verlag Berlin Heidelberg 2013 rib floor system. However, early results indicated that it would be more productive to extend the wall options and to concentrate on a lighter floor system of a similar design to that of the wall and used predominantly in mezzanine and residential loadings, and to add a roof product. Design, theoretical modelling and prototype manufacture of a number of wall types were carried out, leading to a wide range of activities that supported the development of new construction components. These were assembled in various configurations to provide load bearing structures to suit specific needs and purposes as identified by the programme. Theoretical modelling was conducted for a number of configurations to predict the structural performance of roof, wall, and floor products, including the effects of fire (Vilches et al., 2012). Significant research was carried out to develop a suitable filler medium, and recipes were formulated that gave advantages for the CSA panels.

As part of the CSA project, we studied the properties of infill materials, the adhesion between the cement-based material and the steel, and the 
effects of the steel geometries on bonding behaviour, and developed models using theoretical and finite element (FE) analyses to predict the behaviour of bonding between the cement-based material and the galvanised steel.

A reinforced cement-based material is a composite material made up of two components with unequal mechanical properties and physical features. In general, an external load is applied to the cement-based material and reinforcing bars or strips receive their part of the load only from the bond with the surrounding matrix. In such composite structures, the bond and the properties of the interface between different components of the reinforced cement-based material have a significant effect on structural behaviour (Alterman et al., 2011). The bond of the bars or strips to the surrounding matrix can be a key element in determining the ultimate load-carrying capacity of the composite material. Furthermore, the deformation capacity of the components, and hence the redistribution capacity of statistically indeterminate structures, is directly influenced by the bond (Jiang and Qiu, 2009).

However, currently there is no straightforward experimental method to determine these interface properties. This is due mainly to difficulties involved in conducting strain measurements on the bars or strips during the test (Banholzer et al., 2005). Many different alternative test set-ups and experimental techniques have been developed in recent years to investigate the basic mechanisms controlling the properties of a composite interface. One of the most popular experimental techniques is the pull-out test, in which a single bar or strip is pulled out of the surrounding matrix and the corresponding load versus displacement relation is recorded. In this test, the resistance to the debonding and the pull-out processes depends on the bond properties of the composite interface and the interfacial bond area (Pozolo and Andrawes, 2011). Therefore, the load-displacement curve depends on the tested geometric arrangement and does not represent a material-specific relation of the tested composite.

To attain material parameters which are independent of the geometric arrangement, mathematical models have to be applied to analyse the experimentally determined load versus displacement relation and to define the shear force transmission between the reinforcing component and the matrix. Many of these models use systems of equations to analytically describe the processes occurring in a pull-out test, and a so-called bond stress versus slip relation to define the interfacial material properties. The aim of this study was to investigate the bond properties of galvanised steel strips in a cement-based matrix. Only a few studies have been published about the structural bond properties between concrete or cement-based materials and steel, using pull-out tests (Cao and Chung, 2001; De Lorenzis et al., 2002; Chang, 2003; Al-mahmoud et al., 2007). Most previous investigations of bonding behaviour focused mainly on experimental and theoretical studies of shear stress between reinforcing bars and concrete or cement-based specimens (Bouazaoui and Li, 2008; Fang et al., 2006; Khandaker and Hossain, 2008), but not directly on steel strips as in this study. A few FE simulations of pull-out tests are available in the literature (Wu et al., 2009; Wei et al., 2012), but they lack accurate modelling of the interface and bond behaviour.

The main scope of this study was to assess the pull-out behaviour of galvanised steel strips from a cement-based medium and to obtain the local bond stress versus slip relationship. Experimental and theoretical analyses were conducted to investigate the bond properties of the composite structure. FE models were developed in ABAQUS software to predict the bonding behaviour between the cement-based material and the galvanised steel strip and the results are compared with experimental and theoretical techniques. Because bonding is a general problem for wall panel designs and for other uses of cement-based materials that employ steel strips for reinforcement, we investigated the influence of the geometry of the steel strips and the material properties of the matrix on the pull-out behaviour. The results of this research may enable the development of more reliable composite structural assemblies.

\section{Experimental}

In our study, the pull-off test samples included a cement-based material cube $(100 \mathrm{~mm} \times 100 \mathrm{~mm} \times$ $100 \mathrm{~mm}$ ) with a galvanised steel (grade G250 New Zealand Steel) sheet $(50 \mathrm{~mm} \times 0.75 \mathrm{~mm} \times 150 \mathrm{~mm})$ 
standing in the centre. Steel sheets were cleaned and degreased using soapy water, without damaging the coating, before they made contact with the fresh cement-based material. Portland cement type GP was used for all the cement-based mixtures, together with fly ash obtained from the Golden Bay Cement Company of New Zealand. Cement-based material mixtures were prepared with densities of 800,1000 , and $1200 \mathrm{~kg} / \mathrm{m}^{3}$ by using stable foam cement compositions, based on experiments by Kearsley and Mostert (2005).

The cement-based material was obtained by mixing cement, water, and foam in a mortar mixer. The foam, at a density of $56 \mathrm{~kg} / \mathrm{m}^{3}$, was prepared using a foam generator. Ultrafoam was used as the foaming agent and quick gel as the viscosifier. These were mixed with water in the foam generator, until the foam bubble size was uniform and stable (usually $2 \mathrm{~min}$ ). The Portland cement and water were mixed for $5 \mathrm{~min}$. The foam was then added to the cement matrix while stirring, with continual mixing for 1 to $2 \mathrm{~min}$. When the mix of foam cement matrix was uniform, the prepared cement-based material was poured into a test mould with slight vibration to ensure complete filling of the mould.

Under standard conditions, specimens were de-moulded after $24 \mathrm{~h}$ and then moist-cured in a standard curing room for a further $28 \mathrm{~d}$, before testing the samples. Standard cylinders of $100 \mathrm{~mm}$ diameter were used for compressive strength tests, which were carried out in a standard testing machine of $100 \mathrm{kN}$ capacity at a loading displacement rate of $0.1 \mathrm{~mm} / \mathrm{s}$. The cylinders were tested for compressive strength after $28 \mathrm{~d}$ according to the ASTM C39 standard test method for compressive strength of foam concrete specimens.

Pull-out tests were conducted at the Auckland University of Technology, New Zealand to investigate the effect of various parameters such as the hole patterns in the steel strips (Fig. 1), and the mechanical properties of the cement-based material. Different hole patterns were prepared including different numbers of holes $(0,1,2,4,9$, and 14) and holes of different radius or distribution (Table 1). In codifying the hole pattern produced, steel plates were identified as S0, S1-6, S4-3, S9-2, S1-8, S2-8, S14-3, S1-14, $\mathrm{S} 4-7$, and $\mathrm{S} 9-5$, to indicate the number and approximate radius of holes. CBM1, CBM2, and CBM3 represent three types of cement-based mixtures with densities of 800,1000 , and $1200 \mathrm{~kg} / \mathrm{m}^{3}$, respectively. Plates were put in a casting mould and the whole set-up could be easily assembled and disassembled. Steel strips were placed in the middle of the specimens and embedded $50 \mathrm{~mm}$ into the cement-based material among the holding bolts. Before putting the steel strips into the casting mould, they were cleaned with hydrochloric acid to wash away all impurities such as fats and oils.

Pull-out tests were carried out using a universal testing machine equipped with a testing rig with a freely adjustable ball-joint (Fig. 2). Four M10 bolts were embedded in the cubic cement-based material

Table 1 Characteristics of hole patterns

\begin{tabular}{cccc}
\hline Hole pattern & $\begin{array}{c}\text { Number of } \\
\text { holes }\end{array}$ & $\begin{array}{c}\text { Radius of } \\
\text { holes }(\mathrm{mm})\end{array}$ & $\begin{array}{c}\text { Area of } \\
\text { holes }\left(\mathrm{mm}^{2}\right)\end{array}$ \\
\hline S0 & 0 & 0 & 0 \\
S1-6 & 1 & 5.66 & 100.6 \\
S4-3 & 4 & 2.83 & 100.6 \\
S9-2 & 9 & 2.00 & 113.1 \\
S1-8 & 1 & 8.00 & 201.1 \\
S2-8 & 2 & 8.00 & 402.1 \\
S14-3 & 14 & 3.46 & 526.5 \\
S1-14 & 1 & 13.86 & 603.5 \\
S4-7 & 4 & 6.93 & 603.5 \\
S9-5 & 9 & 4.90 & 678.9 \\
\hline
\end{tabular}
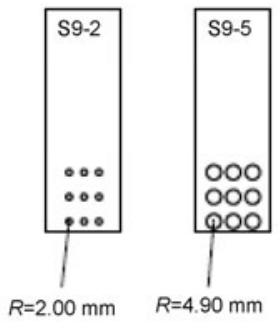

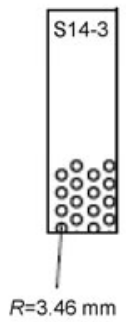

Fig. 1 Patterns of holes in steel strips 
samples and fixed to a plate at the bottom of the cement-based material cube, to hold the sample in place. The adjustable ball-joint for pull-out tests ensures that the pull-out forces are centric to the strips during loading. A load was applied to the metal strip through a mechanical joint and was evenly increased while controlling the displacement at a rate of $0.05 \mathrm{~mm} / \mathrm{s}$. Both the applied load and the displacement of the steel strip were recorded on a computer until the strip was extracted from the cement-based mixture cube.

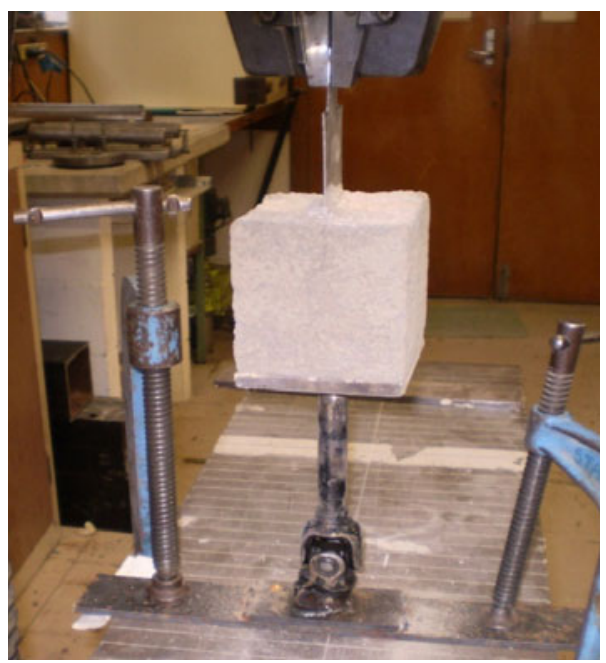

Fig. 2 Testing mechanism with a freely adjustable ball-joint and a plate with embedded-bolts within cement-based material samples

\section{Theoretical analysis}

This section represents a theoretical analysis based on the model previously developed by one of the authors (Chu and Neitzert, 2007). The theoretical analysis sheds light into the bond behaviour by assuming a local bond stress $\tau$ versus slip $s$ relationship. This assumption is then used to obtain the maximum tensile strength and the distributions of bond stress after bond failure. Fig. 3 shows the theoretical model for a pull-out test and its corresponding bond-slip model is depicted in Fig. 4. The subscript 's' stands for steel and ' $c$ ' represents cement-based material. It should be pointed out that the theoretical model developed in this section is for a double lap joint pull-out test (Fig. 3a).

A linear load-displacement $(P-d)$ relationship is assumed for the model as illustrated in Fig. 4a until the pull-out load reaches its maximum, $P_{\max }$. Based on Fig. 4a, it can be assumed that the shear stress along the bonding area increases almost linearly, until it exceeds the maximum shear stress value, $\tau_{\mathrm{m}}$. The initial crack then takes place at the peak load $P_{\max }$, signifying the local bond strength decreases dramatically within a very small slip after reaching the

(a)
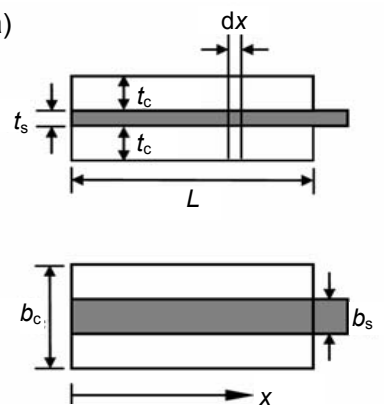

(b)

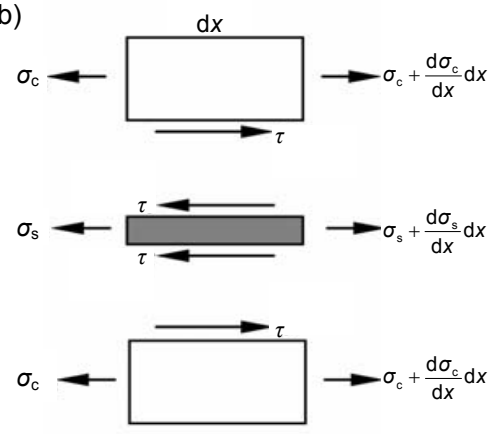

Fig. 3 Pull-out test

(a) Double lap joint pull-out; (b) Stresses
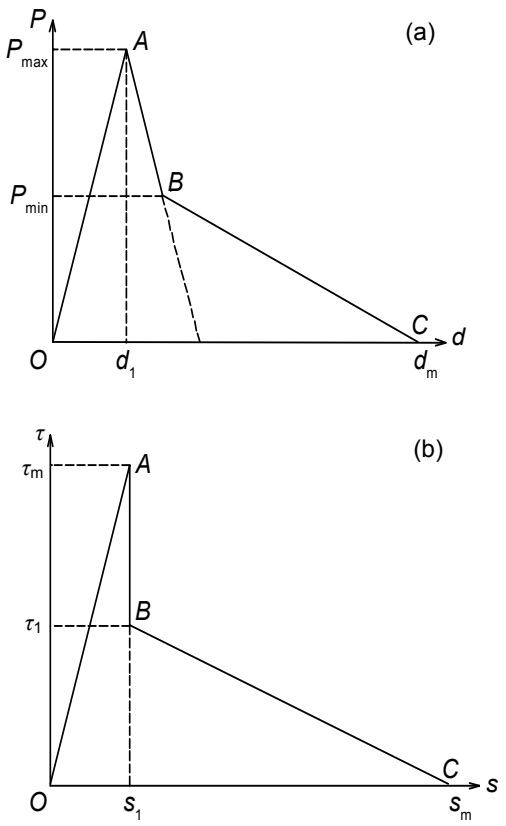

Fig. 4 Analytical model

(a) Load-displacement curve; (b) Bond-slip curve 
maximum value $\tau_{\mathrm{m}}$. As a result, a significant decrease in local bond stress after $\tau_{\mathrm{m}}$ can be seen in Fig. $4 \mathrm{~b}$. Therefore, it can be concluded from Fig. 4 that the corresponding slip $s_{1}$ is equivalent to the displacement $d_{1}$.

In this study, a trilinear local bond-slip model (Fig. 4b) is used to develop the theoretical model of the shear bonding of steel strip and cement-based material. To solve the model numerically, three parameters including $\tau_{\mathrm{m}}, \tau_{1}$, and $s_{\mathrm{m}}$ should be determined. Previously, Yuan et al. (2001) and Wu et al. (2002) derived analytical solutions for pull-out models with relatively simpler bilinear bond-slip models. In this research, the method is further extended to be appropriate for a pull-out test with a trilinear bond-slip model.

The theoretical model assumes homogeneous and linear elastic behavior for both the steel and the cement-based material. It is also assumed that only shear force is applied to the bonding layer. Normal stresses $\sigma_{\mathrm{s}}$ and $\sigma_{\mathrm{c}}$ are considered to be uniform throughout the contact cross-section. The equations of equilibrium for the galvanised steel and the cement-based matrix can be written as

$$
\begin{gathered}
\frac{\mathrm{d} \sigma_{\mathrm{s}}}{\mathrm{d} x}-\frac{2 \tau}{t_{\mathrm{s}}}=0, \\
\sigma_{\mathrm{s}} t_{\mathrm{s}} b_{\mathrm{s}}+2 \sigma_{\mathrm{c}} t_{\mathrm{c}} b_{\mathrm{c}}=0,
\end{gathered}
$$

where $t_{\mathrm{s}}$ and $t_{\mathrm{c}}$ are the thickness of the steel strip and the cement-based cube, respectively; $b_{\mathrm{s}}$ and $b_{\mathrm{c}}$ are the width of the steel strip and the cement-based cube, respectively; $\tau$ is the shear stress; and $\sigma_{\mathrm{s}}$ and $\sigma_{\mathrm{c}}$ are uniform normal stresses in the strip and the cement-based material, respectively. The slip $s$ is defined as the relative displacement of the steel $u_{\mathrm{s}}$ and the cement-based matrix $u_{\mathrm{c}}$, which can be written as a function of $x$ :

$$
s(x)=u_{\mathrm{s}}(x)-u_{\mathrm{c}}(x) .
$$

The following equations can be used to characterise the trilinear bond-slip model presented in Fig. 4b:

$$
\tau= \begin{cases}\frac{\tau_{\mathrm{m}}}{s_{1}} s, & 0 \leq s \leq s_{1}, \\ \frac{\tau_{1}\left(s_{\mathrm{m}}-s\right)}{s_{\mathrm{m}}-s_{1}}, & s_{1} \leq s \leq s_{\mathrm{m}}, \\ 0, & s>s_{\mathrm{m}},\end{cases}
$$

where $\tau_{\mathrm{m}}, \tau_{1}, s_{\mathrm{m}}$, and $s_{1}$ are described in Fig. $4 \mathrm{~b}$. Different numerical solutions can be used for solving the ascending part $O A$ and descending parts $A B$ and $B C$ of Fig. 4a. The crack is assumed to initiate at the local contact point where its bonding stress reaches the maximum shear stress value $\tau_{\max }$. The initial crack is on the loading end of the strip, and $a$ is the crack length (Fig. 5).

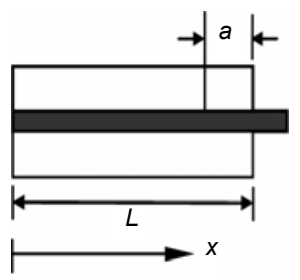

Fig. 5 Crack length $a$

1. Stage $O A(a=0)$ : when the bonding shear stress in the entire bonding region takes place in the ascending part $O A$ of the diagram in the bond-slip model $(a=0)$, the solution is $(0 \leq x \leq L)$ :

$$
\left\{\begin{array}{l}
s(x)=\frac{P \lambda_{1} s_{1} \cosh \left(\lambda_{1} x\right)}{2 b_{\mathrm{s}} \tau_{\mathrm{m}} \sinh \left(\lambda_{\mathrm{l}} L\right)} \\
\tau(x)=\frac{\tau_{\mathrm{m}}}{s_{1}} s(x) \\
\sigma_{\mathrm{s}}(x)=\frac{P}{b_{\mathrm{s}} t_{\mathrm{s}}} \frac{\sinh \left(\lambda_{1} x\right)}{\sinh \left(\lambda_{1} L\right)}
\end{array}\right.
$$

where

$$
\lambda_{1}^{2}=\frac{2 \tau_{\mathrm{m}}}{s_{1}}\left(\frac{1}{E_{\mathrm{s}} t_{\mathrm{s}}}+\frac{b_{\mathrm{s}}}{2 E_{\mathrm{c}} t_{\mathrm{c}} b_{\mathrm{c}}}\right),
$$

where $E_{\mathrm{s}}$ and $E_{\mathrm{c}}$ are the Young's moduli of the galvanised steel and the cement-based material, respectively.

The boundary conditions are:

$$
\begin{cases}\sigma_{\mathrm{s}}=0, & x=0, \\ \sigma_{\mathrm{s}}=\frac{P}{t_{\mathrm{s}} b_{\mathrm{s}}}, & x=L .\end{cases}
$$

2. Stage $A B(0<a<L)$ : now, the bonding shear stress extends in both the ascending section $O A$ and the descending section $A B$ of the bond-slip model. Hence, the numerical solution is subdivided and expressed separately for the ascending region $(0 \leq x \leq L-a)$ 
and descending region $(L-a \leq x \leq L)$ of the $\tau$-s diagram. If $0 \leq x \leq L-a$,

$$
\left\{\begin{array}{l}
s(x)=s_{1} \frac{\cosh \left(\lambda_{1} x\right)}{\cosh \left(\lambda_{1}(L-a)\right)}, \\
\tau(x)=\frac{\tau_{\mathrm{m}}}{s_{1}} s(x), \\
\sigma_{\mathrm{s}}(x)=\frac{2 \tau_{\mathrm{m}}}{\lambda_{1} t_{\mathrm{s}}} \frac{\sinh \left(\lambda_{1} x\right)}{\cosh \left(\lambda_{1}(L-a)\right)} .
\end{array}\right.
$$

\section{If $L-a \leq x \leq L$,}

$$
\left\{\begin{aligned}
s(x)= & \left(\frac{P \lambda_{2}}{2 \tau_{1} b_{\mathrm{s}} \cos \left(\lambda_{2} a\right)}-\tan \left(\lambda_{2} a\right)\right) \\
& \times\left(s_{\mathrm{m}}-s_{1}\right) \sin \left(\lambda_{2}(x-L+a)\right) \\
& -\left(s_{\mathrm{m}}-s_{1}\right) \cos \left(\lambda_{2}(x-L+a)\right)+s_{\mathrm{m}}, \\
\tau(x)= & \frac{\tau_{1}\left(s_{\mathrm{m}}-s\right)}{s_{\mathrm{m}}-s_{1}} \\
\sigma_{\mathrm{s}}(x)= & \frac{2 \tau_{1}}{\lambda_{2} t_{\mathrm{s}}} \cos \left(\lambda_{2}(x-L+a)\right) \\
& \times\left(\frac{P \lambda_{2}}{2 \tau_{1} b_{\mathrm{s}} \cos \left(\lambda_{2} a\right)}-\tan \left(\lambda_{2} a\right)\right) \\
& +\frac{2 \tau_{1}}{\lambda_{2} t_{\mathrm{s}}} \sin \left(\lambda_{2}(x-L+a)\right),
\end{aligned}\right.
$$

where

$$
\lambda_{2}^{2}=\frac{2 \tau_{1}}{S_{\mathrm{m}}-S_{1}}\left(\frac{1}{E_{\mathrm{s}} t_{\mathrm{s}}}+\frac{b_{\mathrm{s}}}{2 E_{\mathrm{c}} t_{\mathrm{c}} b_{\mathrm{c}}}\right) .
$$

The boundary conditions are:

$$
\begin{cases}\sigma_{\mathrm{s}}=0, & x=0, \\ s=s_{1}, & x=L-a, \\ \sigma_{\mathrm{s}}=\frac{P}{t_{\mathrm{s}} b_{\mathrm{s}}}, & x=L .\end{cases}
$$

The crack length $a$ is determined by

$$
P=\left(\frac{\tau_{\mathrm{m}}}{\lambda_{1}} \tanh \left(\lambda_{1}(L-a)\right)+\frac{\tau_{1}}{\lambda_{2}} \tan \left(\lambda_{2} a\right)\right) 2 b_{\mathrm{s}} \cos \left(\lambda_{2} a\right),
$$

assuming $\sigma_{1}$ is continuous for $x=L-a$. For the current theoretical model, $P=P_{\max }=2 b_{\mathrm{s}} \tau_{\mathrm{m}} / \lambda_{1}$, when $a=0, d=s_{1}$; and $P=P_{\min }=2 b_{\mathrm{s}} \tau_{1} / \lambda_{2}$, when $a=L, d=\left(s_{1}-s_{\mathrm{m}}\right) \cos \left(\lambda_{2} L\right)$ $+s_{\mathrm{m}}$.

3. Stage $B C(a=L)$ : when the bonding shear stress in the entire bonding region takes place in the descending section $B C$ of the $\tau$-s diagram, the solution is $(0 \leq x \leq L)$ :

$$
\left\{\begin{array}{l}
s(x)=-\frac{P \lambda_{2}\left(s_{\mathrm{m}}-s_{1}\right)}{2 \tau_{1} b_{\mathrm{s}}} \frac{\cos \left(\lambda_{2} x\right)}{\sin \left(\lambda_{2} L\right)}+s_{\mathrm{m}}, \\
\tau(x)=\frac{\tau_{1}\left(s_{\mathrm{m}}-s\right)}{s_{\mathrm{m}}-s_{1}}, \\
\sigma_{\mathrm{s}}(x)=\frac{P}{b_{\mathrm{s}} t_{\mathrm{s}}} \frac{\sin \left(\lambda_{2} x\right)}{\sin \left(\lambda_{2} L\right)} .
\end{array}\right.
$$

The boundary conditions are similar to Eq. (9). Using the above equations, the shear bonding stresses $\tau_{\mathrm{m}}$ and $\tau_{1}$ as well as the slip, and the normal stress distribution over the bonding region can be defined for any given $s_{\mathrm{m}}$. The experimental results can be used to determine $s_{\mathrm{m}}$ and then the completed local bond-slip model can be implemented to the FE simulation.

\section{Finite element simulation}

The pull-out test was further studied by FE simulations to investigate the possibility of using the local bond-slip behaviour for structural analysis of composite structures. A 3D FE model was developed through the mainframe ABAQUS release 6.12 for this purpose. This is an implicit analysis code suitable for modelling both material and geometric nonlinearities, and has good contact modelling. The FE analysis comprised an elastic-plastic simulation of the pull-out process and the determination of the loaddisplacement curve in the steel strip. Appropriate boundary conditions were applied to the model and the non-linear geometry NLGEOM option in ABAQUS was used throughout the analysis.

A user-defined subroutine is used to define the interfacial constitutive behaviour and provides a novel numerical model for simulating the bond-slip behaviour of a composite structure. In this way, any special or proprietary interfacial constitutive behaviour can be defined through a user subroutine 'UINTER' written 
in FORTRAN in ABAQUS/Standard, which may include both normal and tangential behaviours. This feature provides a robust tool for simulating bond-slip behaviour. User subroutine UINTER will be called for each contact constraint location of affected contact pairs in every increment of the ABAQUS/Standard analysis. The input to this user subroutine includes the current relative position of a particular constraint point on the slave surface with respect to the corresponding closest point on the master surface, as well as the incremental relative motion between these two points. In our study, the pull-out tests were simulated by applying the user-defined shear constitutive behaviours $(\tau-s)$ obtained from the test results and analytical solutions. The normal direction constitutive behaviour is modelled using the penalty approach once the interaction surfaces are in contact; otherwise the normal strength is zero.

The FE simulations were conducted for all the hole patterns depicted in Fig. 1 and the FE results were compared with experimental results. To minimize computational time, a quarter of the model was simulated due to symmetry, and appropriate constraints were imposed on the symmetry plan. The FE mesh was uniform and was generated using a C3D8R element which is an 8-node linear brick with reduced integration and hourglass control. The material properties of the galvanised steel were determined through a tensile test of the steel specimen. The concrete damaged plasticity model was assumed for the cement-based material. This model provides a general capability for modelling cement-based materials and other quasi-brittle materials in all types of structures. It uses concepts of isotropic damaged elasticity in combination with isotropic tensile and compressive plasticity to represent the inelastic behaviour of a cement-based matrix. The concrete damaged plasticity model is based on the assumption of scalar (isotropic) damage, and is designed for applications in which the concrete or the cementbased materials are subjected to arbitrary loading conditions. The model takes into consideration the degradation of the elastic stiffness induced by plastic straining both in tension and compression. It also accounts for stiffness recovery effects under cyclic loading. Figs. 6 and 7 show the distribution of the von-Mises stress in the CBM3 cube and the strips S0 and S9-5 at $d=6 \mathrm{~mm}$.

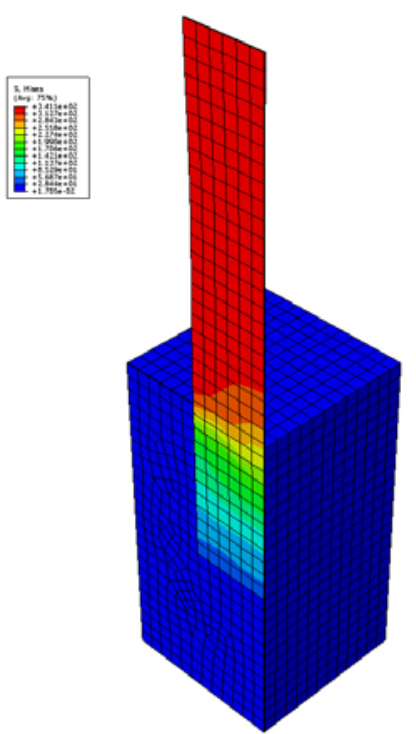

Fig. 6 Distribution of von Mises stress in pull-out test of the steel strip S0 and CBM3 at $d=6 \mathrm{~mm}$

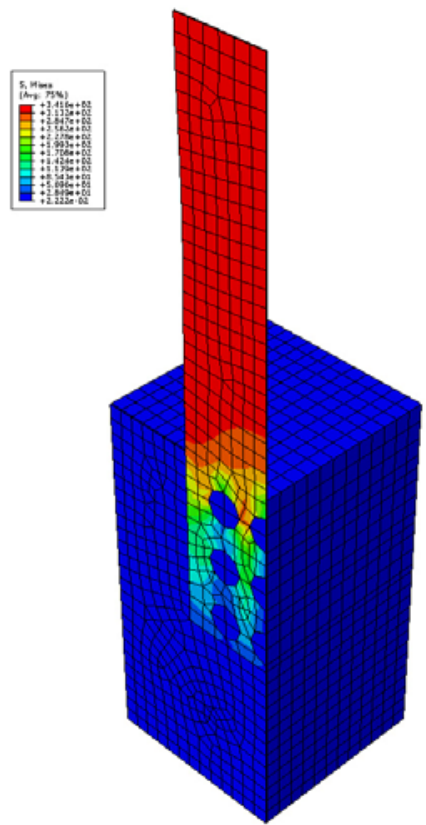

Fig. 7 Distribution of von Mises stress in pull-out test of the steel strip S9-5 and CBM3 at $d=6 \mathrm{~mm}$

\section{Results and discussion}

The experimental, theoretical, and FE results of the pull-out tests using the steel strips with different hole patterns and three different types of the cement-based materials are presented in this section. The aim of the pull-out experiments was to study the 
effect of ten different hole patterns (Fig. 1) and mechanical properties of the cement-based material on the bonding between the steel and the cement-based matrix. The reference hole area was $100.6 \mathrm{~mm}^{2}$ with a $11.32 \mathrm{~mm}$ diameter. The reference area was increased up to 6.75 times, to verify the effect of the anchorage of the cement-based material embedded into holes in various designs.

Ninety pull-out samples were prepared, including those with different numbers of holes, diameters, distributions of holes in the steel strips, and different densities of the cement-based material. Three specimens for each single set were tested to determine the bonding strength during pull-out tests. The maximum pull-out forces as averages for each single set were measured during pull-out tests, and the outcomes are shown in Fig. 8. The compressive strength of the cement-based compositions CBM1, CBM2, and CBM3 were $0.91,2.97$, and $8.8 \mathrm{MPa}$, respectively. These results show that the strength of the cement-based material is a significant parameter for bonding behaviour. The analysis of the test results led to the conclusion that the pull-out forces increase with increasing strength of the cement-based material. Based on the results, holes cut into the steel strips can be used to improve the pull-out forces for cement-based materials with higher strength; however, a negative effect on the pull-out forces was found for lighter cement-based materials. In CBM1, the values of maximum pull-out strength generally decreased as the area of the holes in the steel strips increased (Fig. 8). The main reason for this was that the area of chemical adhesion was reduced due to the holes cut into the steel strips. The mechanical interlock introduced by the cement-based material inside the holes was not enough to compensate for the loss of adhesion in the weaker matrix. Thus, the holes made in the steel strips are recommendable beyond a certain threshold value for greater compressive strength of the matrix.

In Fig. 9, the pull-out results are displayed as a function of the hole diameter for the CBM3 mixtures. There was a stronger correlation between the pull-out force and the sum of the diameters of the holes $\left(R^{2}=\right.$ 0.9044) for CBM3 samples. CBM1 and CBM2 samples also showed the same trend. From Fig. 9, it is clear that the pull-out forces increased nearly linearly with increasing hole diameter.
The relationship between the sum of the hole circumference areas and the pull-out forces was also analyzed (Fig. 10), to better describe the relationship between strip geometry and pull-out forces. The strips with the greatest circumference areas of all holes had higher pull-out forces and the increase was nearly linear.

The normalized load-displacement curves for the original pull-out test of the steel strip without holes

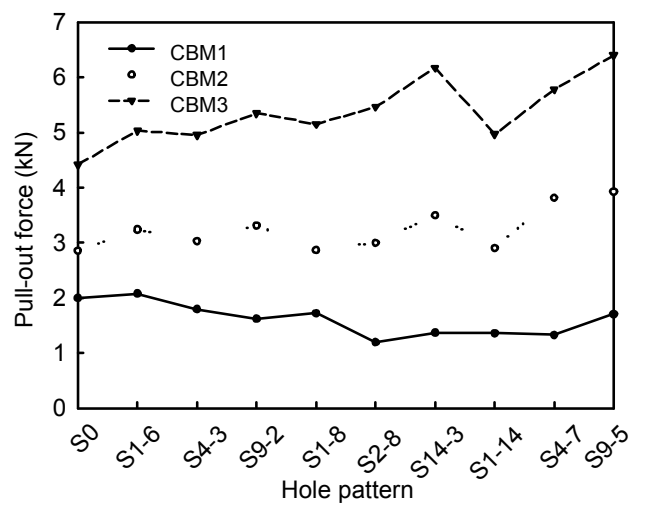

Fig. 8 Effect of strip geometry on maximum pull-out force

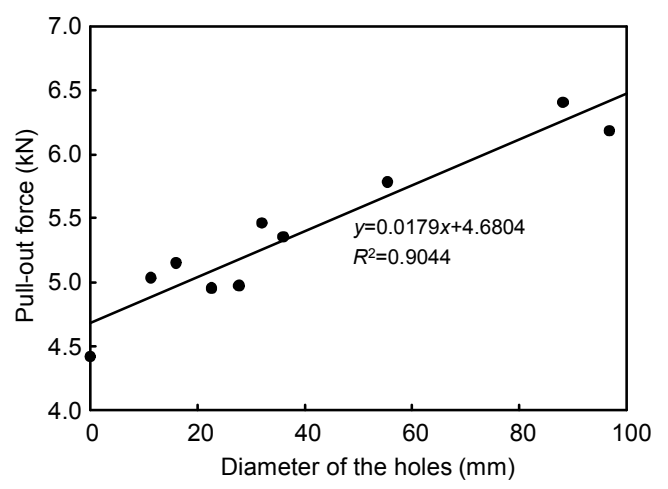

Fig. 9 Effect of the total diameter of the holes on the pull-out force for CBM3

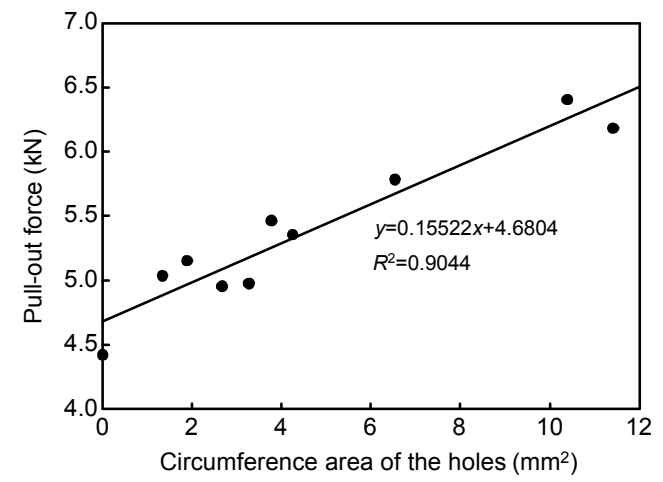

Fig. 10 Effect of the circumference area of the holes on the pull-out force for CBM3 
(S0) is shown in Fig. 11 for experimental, theoretical, and FE simulation analyses. For brevity, the results of only CBM3 are presented; however, CBM1 and CBM2 showed nearly the same trend. The results show very good agreement, with the FE model predicting a slightly higher pull-out force. The theoretical model developed in Section 3 is valid only for the pull-out test of a steel strip without holes in terms of predicting the load-displacement curve. However, the

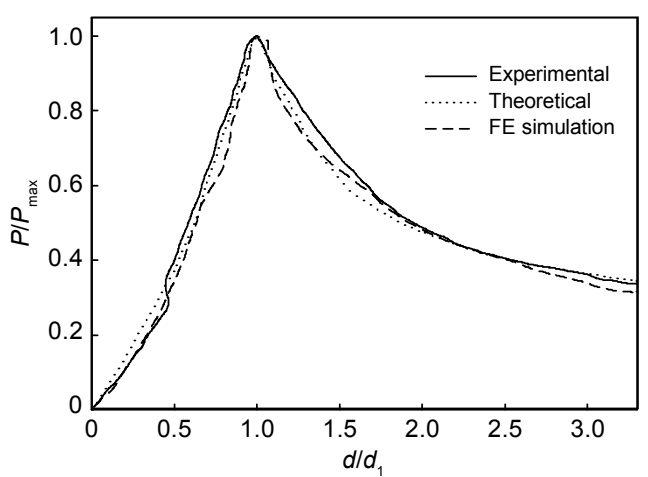

Fig. 11 Comparison of experimental, theoretical, and FE load-displacement curves for the pull-out test of the steel strip S0
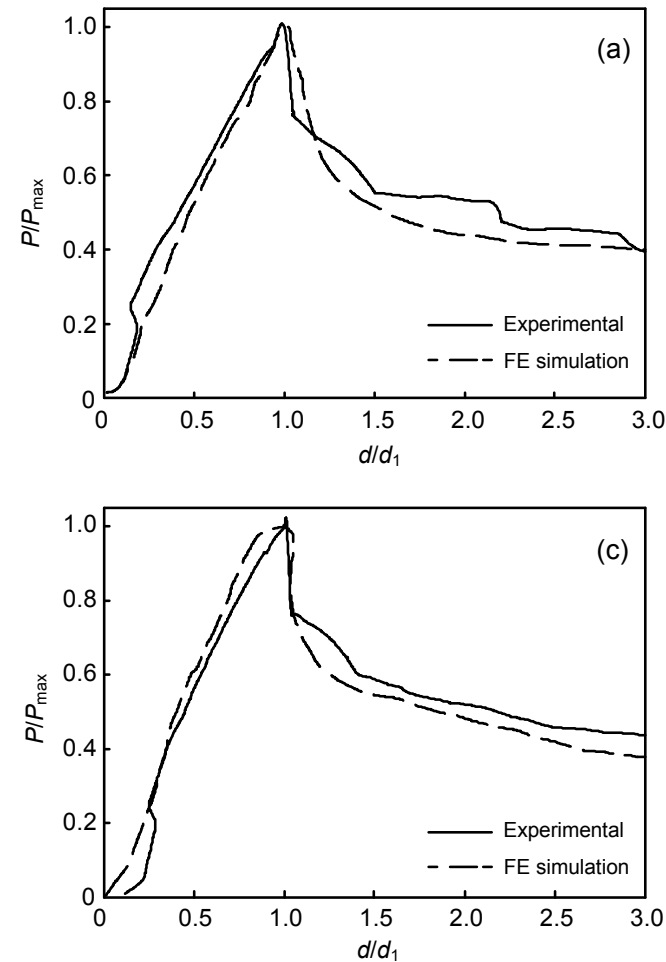

Fig. 12 Normalized load-displacement curves for the pull-out test of the steel strips in CBM3

Fig. 12 Normalized load-displacement curves for the pull-out test
(a) S1-6; (b) S2-8; (c) S4-3; (d) S9-5
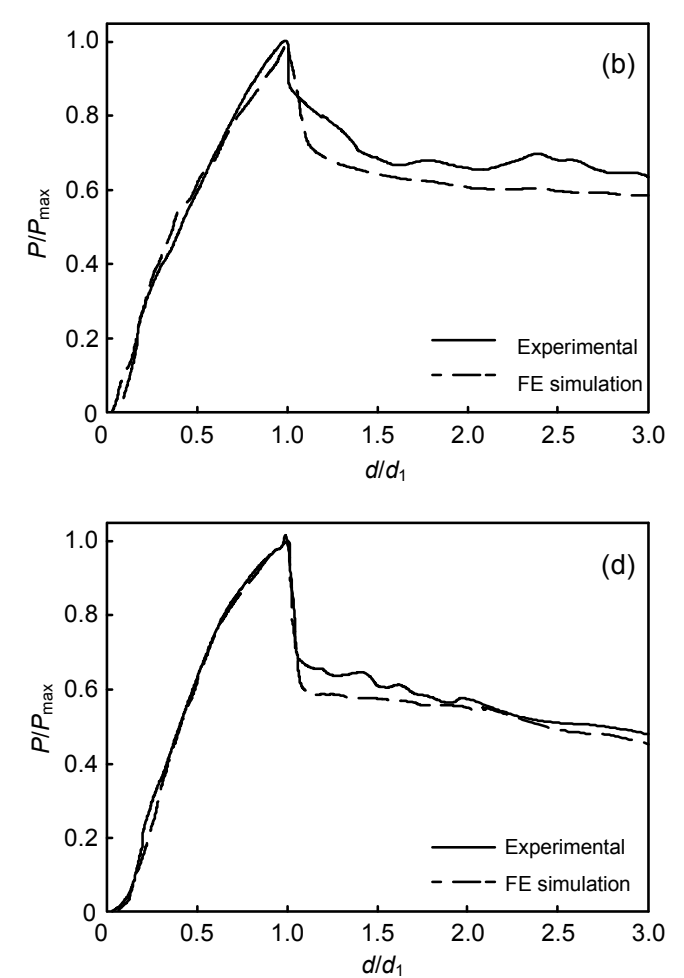

bond-slip relationship obtained from this model can be used in FE simulations of all other strip geometries through the user-defined subroutine UINTER. The load-displacement curves obtained from the experiments and the FE simulations for all other strip geometries were also compared and showed very good correlations. For brevity, the results for only four cases are presented in Figs. 12, 13, and 14 for CBM3, CBM2, and CBM1, respectively. However, all other cases showed the same trend with very good agreement. The load dropped suddenly after the maximum value was achieved and then started to decrease slowly, indicating that the loading capacity still existed even after the debonding. Pull-out experiments showed that a long softening stage $\left(>20 d_{1}\right)$ existed after the maximum load (Fig. 4a). The maximum pull-out forces obtained from experimental and FE analyses are compared in Figs. 15, 16, and 17 (p.853) for all hole patterns in CBM3, CBM2, and CBM1 cubes, respectively. In general, the FE simulations tended to predict higher pull-out forces (with the exception of 4-hole patterns in CBM2); however, the differences in all cases were less than $7 \%$. 

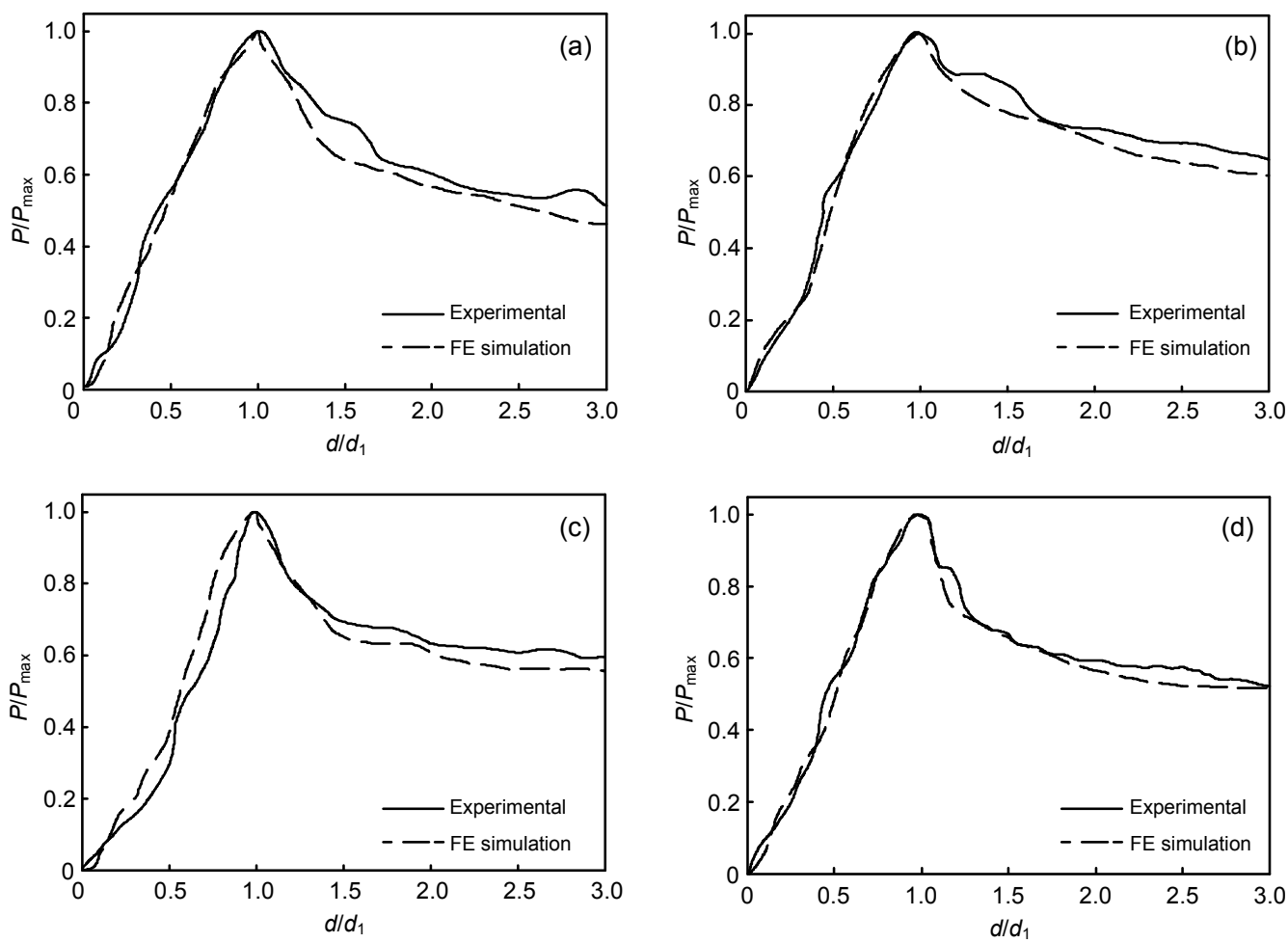

Fig. 13 Normalized load-displacement curves for the pull-out test of the steel strips in CBM2 (a) S1-6; (b) S2-8; (c) S4-3; (d) S9-5
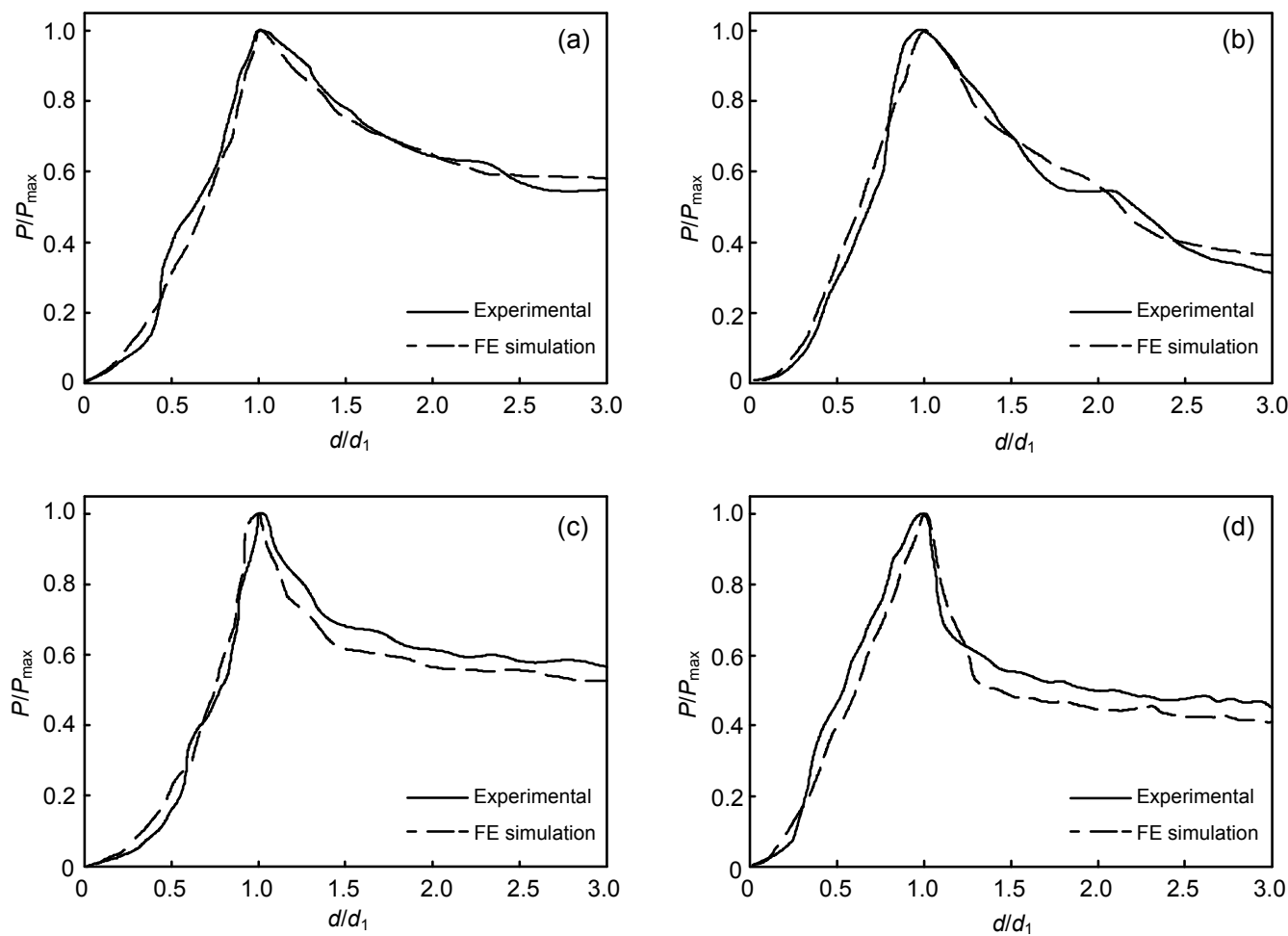

Fig. 14 Normalized load-displacement curves for the pull-out test of the steel strips in CBM1 (a) S1-6; (b) S2-8; (c) S4-3; (d) S9-5 


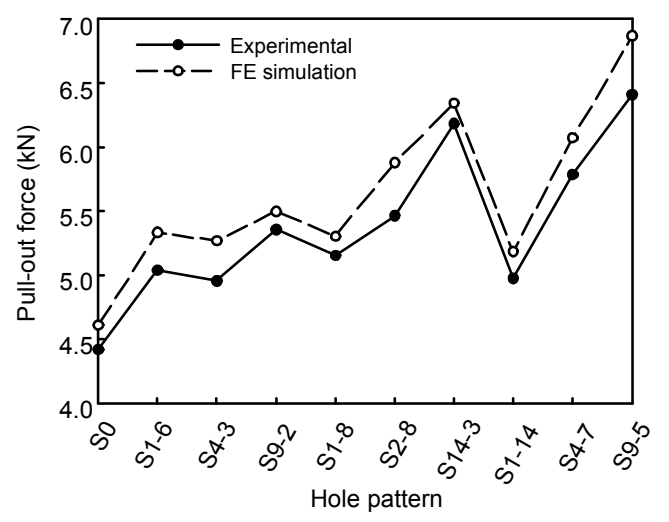

Fig. 15 Comparison of experimental and FE simulation pull-out forces for different strip geometries for CBM3

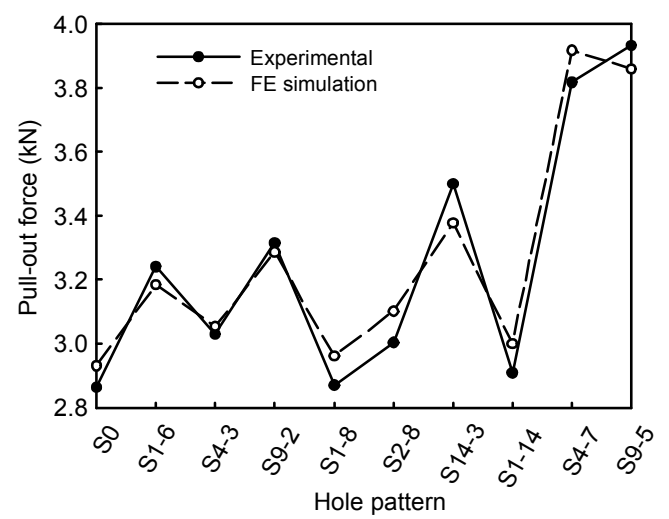

Fig. 16 Comparison of experimental and FE simulation pull-out forces for different strip geometries for CBM2

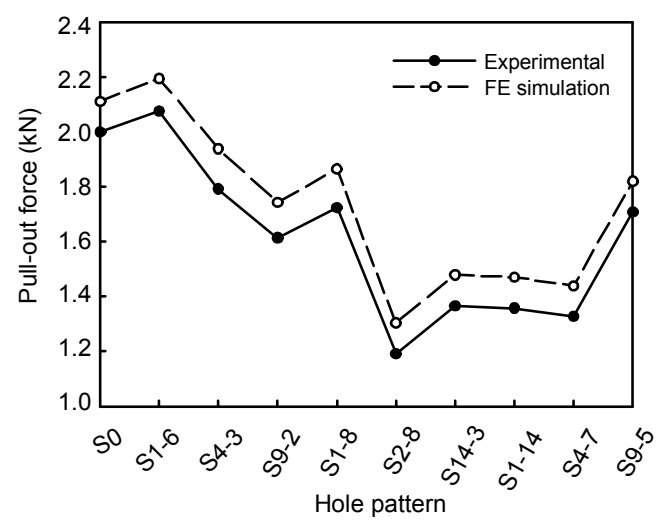

Fig. 17 Comparison of experimental and FE simulation pull-out forces for different strip geometries for CBM1

After the pull-out tests, it was observed that failure occurred in two different modes. One mode involved the splitting of the cement-based material surrounding the steel strip (usually observed in
CBM1), and the other involved the shearing of the reinforcement against the surrounding cement-based material (usually observed in CBM2 and CBM3). These are considered as brittle failures, in which the load decreases after reaching the maximum, and are initiated by the formation and growth of cracks. In general, the failure mechanism in pull-out tests was a combination of concrete cone failure and bond failure.

Fig. 18 shows the distribution of the shear stress $\tau$, slip $s$, and normal stress $\sigma_{\mathrm{s} x}$ in the steel strip over the bonding area obtained from the analytical model and the FE simulation, corresponding to four different points of the $P$ - $d$ curve of the pull-out test of the steel strip without holes ( $\mathrm{S} 0$ as shown in Fig. 11). For this particular example, $\tau_{\mathrm{m}}=0.86 \mathrm{MPa} ; \tau_{1}=0.37 \mathrm{MPa}$; $s_{1}=2.05 \mathrm{~mm}$; and $s_{\mathrm{m}}=40 \mathrm{~mm}$. $\tau_{\text {ave }}$ is determined by calculation of $P_{\max }$ divided by the contact area. $s_{\mathrm{m}}$ is an estimated value and is assumed to be equal to $d_{\mathrm{m}}$, which is the maximum displacement on the $P-d$ curve. All the values increased with increasing distance to the free end $x$, and the stresses and slip reached their maximum values at that end. The theoretical and FE analyses showed a very good correlation. The differences between analytical and FE results increased over the whole bonding area as $x$ increased. In the analytical model, it is assumed that the bonding layer is exposed only to the shear force and that the normal stresses are uniformly distributed over the crosssection in both the cement-based material and the steel strip. However, the FE simulation showed that the normal stresses, particularly in the cement-based material, were actually not uniformly distributed over the cross-sections, indicating that a partially shear condition existed in the bonding layer. Therefore, the applied load tended to contribute not only to the shear debonding of the layer but also to the bending effect.

The break point in Fig. 18c was due to the crack length $a$ that continues to increase throughout the analysis. At the cracked area $(L-a<x<L)$, the shear stress was constant $\left(\tau=\tau_{1}\right)$; while at the bonded area ( 0 $<x<L-a$ ), the shear stresses kept climbing, although the distributions were different in the analytical and FE models. This also affected the distribution of slip $s$. Similarly, the normal stress $\sigma_{\mathrm{s} x}$ distribution is shown for both models. The normal stress $\sigma_{\mathrm{s} x}$ was softened at the cracked area as a result of the reduced bonding 

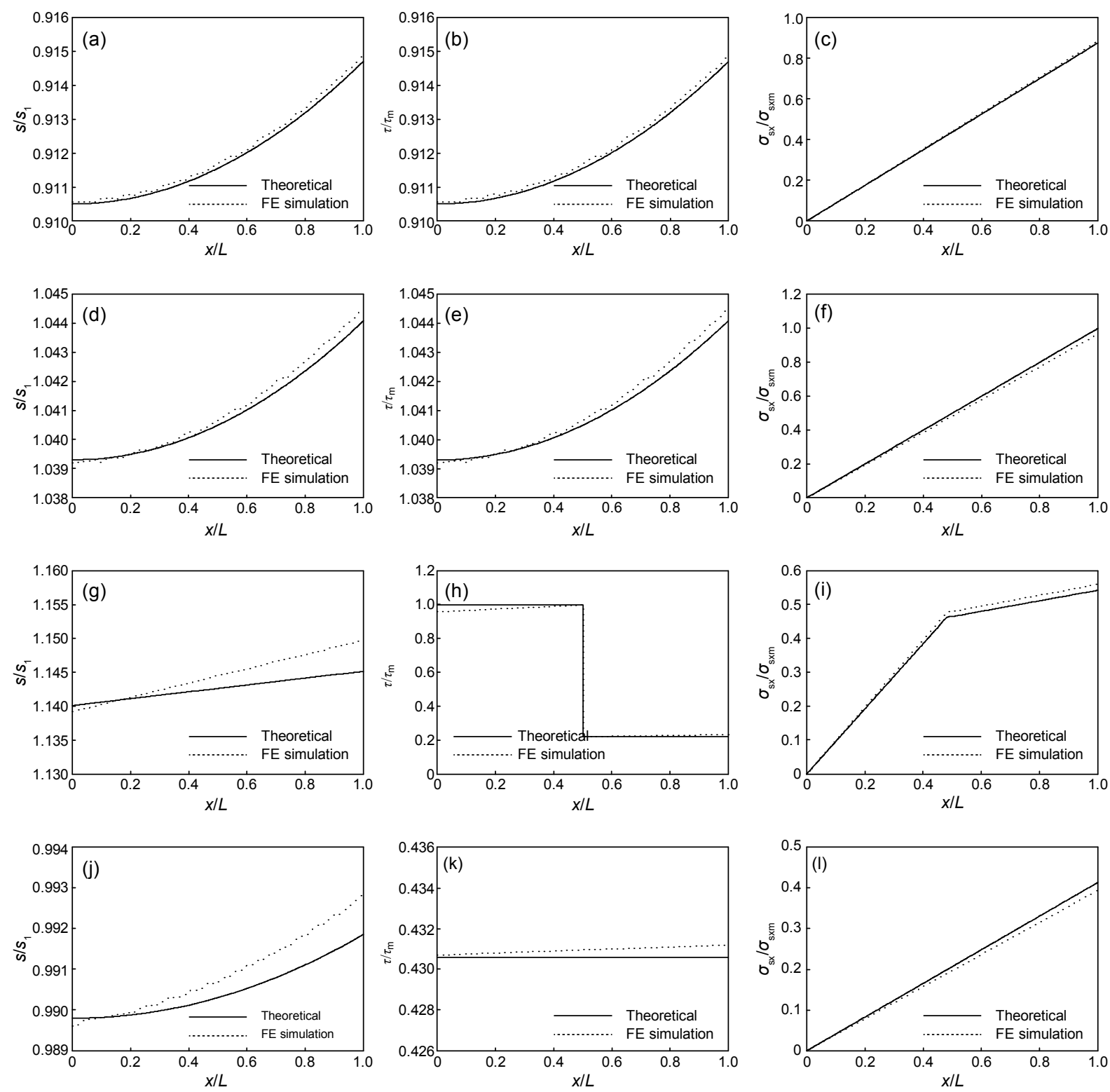

Fig. 18 Distribution of slip, shear stress, and normal stress in the steel strip S0 over the bonding area at different loading stages $\left(\sigma_{\mathrm{s} x \mathrm{~m}}=\boldsymbol{P}_{\max } /\left(\boldsymbol{b}_{\mathrm{s}} t_{\mathrm{s}}\right)\right)$

(a)-(c) $d / d_{1}=0.85$; (d)-(f) $d / d_{1}=1.00$; (g)-(i) $d / d_{1}=1.45$; (j)-(l) $d / d_{1}=2.45$

strength, which led to a continuous decrease in the applied load. When the crack length $a$ exceeded a certain value, the elastic elongation within the cracked area of steel decreased with the decrease in the applied load, so the total slip $s$ reduced accordingly. This phenomenon may not have been easy to capture or identify in the experiments due to the limitation of the apparatus and the insignificance of the differences.

\section{Conclusions}

This paper presents the experimental, theoretical, and FE simulation results of pull-out tests of steel strips with different geometries in cement-based material with different mechanical properties. A theoretical method to study the pull-out behaviour of the steel strips in the cement-based material is presented and a local bond-slip relationship is determined using 
experimental and theoretical analyses. The bond-slip relationship is then implemented in an FE simulation through the user-defined subroutine of ABAQUS software. Good correlation was found among the experimental, theoretical and FE results. A comparative analysis of the pull-out tests confirmed significant improvements in pull-out forces for strips with holes over those without holes. Generally, pull-out forces were influenced by chemical adhesion and mechanical interlock due to the anchorage provided by the cement-based material which goes through the holes. The diameter and the circumference area of the holes were found to have strong influences on the pull-out forces with nearly linear trends. The holes in the steel plates contributed significantly to increasing the pull-out forces for stronger matrices, but the contribution of the holes turned negative when using a weak matrix. These results imply that the anchorage given by the holes contributes to raising the overall adhesion between the cement-based material and the steel strips. In contrast, the adhesion between a weak matrix and steel strips with holes is affected adversely, mainly due to the lack of strength of the cement-based material. The proposed equations and FE simulations presented in this paper could provide a good estimation of the bond strength between the steel and the cement-based material, and can be used for parametric studies without complex experimental design. The numerical analysis conducted in this paper is suitable for designing novel composite structural assemblies for structural applications, where the strength and behaviour of the bond is very important.

\section{References}

Al-mahmoud, F., Castel, A., François, R., Tourneur, C., 2007. Effect of surface pre-conditioning on bond of carbon fibre reinforced polymer rods to concrete. Cement \& Concrete Composites, 29(9):677-689. [doi:10.1016/j.cemconcomp. 2007.04.010]

Alterman, D., Vilches, J., Neitzert, T., 2011. An analysis of the bonding energy through pull-out tests for aerated concrete with various steel strip geometries. Advanced Materials Research, 275:55-58. [doi:10.4028/www.scientific.net/ AMR.275.55]

Banholzer, B., Brameshuber, W., Jung, W., 2005. Analytical simulation of pull-out tests-the direct problem. Cement \& Concrete Composites, 27(1):93-101. [doi:10.1016/j. cemconcomp.2004.01.006]

Bouazaoui, L., Li, A., 2008. Analysis of steel/concrete interfacial shear stress by means of pull out test. International Journal of Adhesion \& Adhesives, 28(3):
101-108. [doi:10.1016/j.jjadhadh.2007.02.006]

Cao, J., Chung, D., 2001. Degradation of the bond between concrete and steel under cyclic shear loading, monitored by contact electrical resistance measurement. Cement and Concrete Research, 31(4):669-671. [doi:10.1016/S00088846(01)00462-8]

Chang, J., 2003. Bond degradation due to the desalination process. Construction and Building Materials, 17(4): 281-287. [doi:10.1016/S0950-0618(02)00113-7]

Chu, X.T., Neitzert, T., 2007. Experimental and numerical modelling of interfacial behaviour between galvanised steel and aerated concrete. International Journal of Modelling, Identification and Control, 2(3):208-218. [doi:10. 1504/IJMIC.2007.014938]

De Lorenzis, L., Rizzo, A., La Tegola, A., 2002. A modified pull-out test for bond of near-surface mounted FRP rods in concrete. Composites Part B: Engineering, 33(8):589603. [doi:10.1016/S1359-8368(02)00052-5]

Fang, C., Lundgren, K., Plos, M., Gylltoft, K., 2006. Bond behaviour of corroded reinforcing steel bars in concrete. Cement and Concrete Research, 36(10):1931-1938. [doi:10.1016/j.cemconres.2006.05.008]

Jiang, D., Qiu, H., 2009. Simplified solution of the slip between rebar and concrete based on pull-out test. Journal of Southeast University (Natural Science Edition), 39(4): 830-835 (in Chinese).

Kearsley, E.P., Mostert, H.F., 2005. Designing Mix Composition of Foam Concrete with High Fly Ash Contents. Use of Foamed Concrete in Construction, International Conference Held at the University of Dundee, Scotland, UK, p.29-36.

Khandaker, M., Hossain, A., 2008. Bond characteristics of plain and deformed bars in lightweight pumice concrete. Construction and Building Materials, 22(7):1491-1499. [doi:10.1016/j.conbuildmat.2007.03.025]

Pozolo, A., Andrawes, B., 2011. Analytical prediction of transfer length in prestressed self-consolidating concrete girders using pull-out test results. Construction and Building Materials, 25(2):1026-1036. [doi:10.1016/j. conbuildmat.2010.06.076]

Vilches, J., Ramezani, M., Neitzert, T., 2012. Experimental investigation of the fire resistance of ultra lightweight foam concrete. International Journal of Advanced Engineering Applications, 1(4):15-22.

Wei, G., Liu, G., Xu, C., Sun, X., 2012. Finite element simulation of perfect bonding for single fiber pull-out test. $A d$ vanced Materials Research, 418-420:509-512. [doi:10. 4028/www.scientific.net/AMR.418-420.509]

Wu, J.J., Cheng, X.H., Qi, Y., 2009. Simulation and analysis of single fibre pull-out test with FEM. Journal of Shanghai Jiaotong University, 43(10):1601-1604, 1608.

Wu, Z., Yuan, H., Niu, H., 2002. Stress transfer and fracture propagation in different kinds of adhesive joints. Journal of Engineering Mechanics, 128(5):562-573. [doi:10. 1061/(ASCE)0733-9399(2002)128:5(562)]

Yuan, H., Wu, Z., Yoshizawa, H., 2001. Theoretical solutions on interfacial stress transfer of externally bonded steel/ composite laminates. Structural Engineering/Earthquake Engineering, 18(1):27s-39s. 